\title{
Effect of fat mass and lean mass on bone mineral density in postmenopausal and perimenopausal Thai women
}

This article was published in the following Dove Press journal:

International Journal of Women's Health

26 February 2013

Number of times this article has been viewed

\author{
Sirianong Namwongprom' \\ Sattaya Rojanasthien ${ }^{2}$ \\ Ampica Mangklabruks ${ }^{3}$ \\ Supasil Soontrapa ${ }^{4}$ \\ Chanpen Wongboontan ${ }^{5}$ \\ Boonsong \\ Ongphiphadhanakul ${ }^{6}$ \\ 'Clinical Epidemiology Program \\ and Department of Radiology, \\ ${ }^{2}$ Department of Orthopaedics, \\ ${ }^{3}$ Department of Internal Medicine, \\ Faculty of Medicine, Chiang Mai \\ University, Chiang Mai, ${ }^{4}$ Department \\ of Orthopaedics, Faculty of Medicine, \\ Khon Kaen University, Khon Kaen, \\ ${ }^{5}$ Department of Radiology, Faculty \\ of Medicine, Chiang Mai University, \\ Chiang Mai, ${ }^{6}$ Department of Internal \\ Medicine, Faculty of Medicine, \\ Ramathibodi Hospital, Mahidol \\ University, Bangkok, Thailand
}

Correspondence: Sirianong Namwongprom

Department of Radiology, Faculty of Medicine, Chiang Mai University, Chiang Mai 50200, Thailand

Tel +66 53945458

Email snamwong@med.cmu.ac.th
Background: The purpose of this study was to investigate the association between fat mass, lean mass, and bone mineral density (BMD) in postmenopausal and perimenopausal Thai women. Methods: A cross-sectional study was conducted in 1579 healthy Thai women aged 40-90 years. Total body, lumbar spine, total femur, and femoral neck BMD and body composition were measured by dual $\mathrm{x}$-ray absorptiometry. To evaluate the associations between fat mass and lean mass and various measures of BMD, multivariable linear regression models were used to estimate the regression coefficients for fat mass and lean mass, first in separate equations and then with both fat mass and lean mass in the same equation.

Results: Among the study population, 1448 subjects (91.7\%) were postmenopausal and $131(8.3 \%)$ were perimenopausal. In postmenopausal women, after controlling for age, height, and duration of menopause, both fat mass and lean mass were positively correlated with BMD when they were analyzed independently of each other. When included in the same equation, both fat mass and lean mass continued to show a positive effect, but lean mass had a significantly greater impact on BMD than fat mass at all regions except for total body. Lean mass but not fat mass had a positive effect on BMD at all skeletal sites except the lumbar spine, after controlling for age and height in perimenopausal women.

Conclusion: Lean mass had a significant beneficial effect on BMD in both postmenopausal and perimenopausal women and can be considered as one of the determinants of bone mass. The effect of the fat mass was related to menopausal status, but only demonstrated a positive impact in perimenopausal women.

Keywords: bone mineral density, fat mass, lean mass

\section{Introduction}

Osteoporosis and obesity are two public health problems that are growing in prevalence worldwide, including in Thailand. Interestingly, these two body composition disorders, once believed to be unrelated to each other, share several features at both the molecular and clinical levels, and are also correlated with similar environmental factors. ${ }^{1}$ Several studies have suggested that body weight or body mass index is positively correlated with bone mineral density (BMD) or bone mineral content. ${ }^{2-6}$ These findings indicate that a higher body mass results in more skeletal loading, which enhances the differentiation of osteoblasts. Body mass is composed of three compartments, ie, lean mass, fat, and bone. Therefore, recent publications have focused on the effect of fat mass and lean mass on BMD rather than total body weight or body mass index. Many publications have demonstrated the independent effect of fat mass and lean mass on BMD. ${ }^{7-14}$ Other studies have also indicated that fat mass has a beneficial effect on bone.,.$^{3,15-19}$ Not only 
fat mass, but also lean mass, which contributes to body composition, may have an effect on BMD. Several studies have even concluded that lean mass has a greater effect than fat mass on BMD. ${ }^{7,9,11,13,15,20-22}$ Based on current knowledge, it is unclear whether fat mass or lean mass has the major effect on BMD, and there is little knowledge about the relationship of body composition (fat mass and lean mass) and its effect on BMD in postmenopausal and perimenopausal women. Further, fat mass and lean mass could have different roles in determining BMD at different skeletal sites. The present study investigated the effect of fat mass and lean mass on BMD at several skeletal sites in postmenopausal and perimenopausal women.

\section{Materials and methods Subjects}

This cross-sectional study was performed in 1584 healthy postmenopausal and perimenopausal Thai women, who had BMD measured at the lumbar spine and left hip and body composition (fat mass and lean mass) recordings by dual x-ray absorptiometry (Discovery A, Hologic Inc, Bedford, MA) in the Department of Radiology, Faculty of Medicine, Chiang Mai University, between January 2008 and December 2010. Postmenopausal is defined as the time after which a woman has experienced 12 consecutive months of amenorrhea. Perimenopausal is defined as the time at which a woman is experiencing symptoms characteristic of the perimenopause when her menstrual periods start changing up to 12 consecutive months prior to amenorrhea. All subjects were screened with a questionnaire and careful history-taking. Subjects were excluded from the study if they had conditions that might affect BMD, including malignant tumors, thyrotoxicosis, parathyroid diseases, oophorectomy, renal tubular acidosis, hyperprolactinemia, rheumatoid arthritis, ankylosing spondylitis, hematologic disease, and malabsorption syndromes. We also excluded women who had been receiving therapies that interfere with bone metabolism (eg, glucocorticoids, estrogens, thyroid hormone, fluoride, bisphosphonates, calcitonin, barbiturates, and antiseizure medications). Subjects with structural abnormalities, such as a history of surgery, evidence of degenerative disease, fractures, and artifacts demonstrated on BMD images or other imaging modalities at the lumbar spine or hip were also excluded. The study protocol was approved by the ethics committee of the Faculty of Medicine, Chiang Mai University.

\section{Anthropometric measurements}

Standing height in $\mathrm{cm}$ and weight in $\mathrm{kg}$ were recorded for all subjects. Body mass index was calculated as $\mathrm{kg} / \mathrm{m}^{2}$.

\section{BMD and body composition measurements}

The BMD was measured at the lumbar spine (L1-L4), femoral neck, total hip, and total body. Fat mass, lean mass, and percentage body fat were derived from a whole body scan. All measurements were performed using the Hologic Discovery A software version 12.3 by experienced technologists and finally interpreted by clinical densitometrists certified by the International Society for Clinical Densitometry. The densitometer was standardized by a phantom each time before measurement. Quality control for the absorptiometry machine was checked daily.

\section{Statistical analysis}

Statistical analysis was performed using Stata version 11.0 (StataCorp LP, College Station, Texas). The results of the statistical analysis were expressed as the mean \pm standard deviation. Pearson's correlation coefficient was used to examine relationships between variables. Multivariate linear regression models were used to estimate the regression coefficients for fat mass and lean mass, first in separate equations and then with both fat mass and lean mass in the same equation to evaluate associations between fat mass, lean mass, and various measures of BMD. In addition, body weight and body mass index were omitted to avoid entering variables that were highly interrelated and to separate the effects of fat mass and lean mass. Age, height, and menopause were controlled for by inclusion in regression equations. A regression equation $[\mathrm{BMD}=\mathrm{f}$ (fat mass, lean mass, age, height)] was used to estimate the independent effects of fat mass and lean mass relative to each other in perimenopausal women. For postmenopausal women, the regression equation $[\mathrm{BMD}=\mathrm{f}$ (fat mass, lean mass, age, menopause age, height)] was used. $P \leq 0.05$ was considered to be statistically significant.

\section{Results}

Basic characteristics, BMD, and body composition variables for the subjects are shown in Table 1. Among the study population, 136 subjects (8.6\%) were perimenopausal and 1448 (91.4\%) were postmenopausal. The average age was 63.1 years and 49.2 years for postmenopausal and perimenopausal subjects, respectively. For postmenopausal women, the average age at menopause was 48.7 years, with an average menopause duration of 14.3 years. The postmenopausal women were shorter, had a lower BMD at all regions of interest, and had a lower mean body mass index than perimenopausal women. There was no statistically significant difference in fat mass and lean mass between the two groups of women. Table 2 details 
Table I Baseline characteristics and anthropometric variables of the perimenopausal and postmenopausal women

\begin{tabular}{|c|c|c|c|}
\hline Characteristics & $\begin{array}{l}\text { Postmenopausal } \\
\text { women } \\
(n=1,448)\end{array}$ & $\begin{array}{l}\text { Perimenopausal } \\
\text { women } \\
(n=|3|)\end{array}$ & $P$-value \\
\hline Age (years) & $63.1 \pm 9.5$ & $49.2 \pm 4.4$ & $<0.001$ \\
\hline Height (cm) & $150.7 \pm 6.0$ & $153.6 \pm 5.0$ & $<0.001$ \\
\hline Weight (kg) & $54.2 \pm 9.3$ & $54.3 \pm 7.5$ & 0.844 \\
\hline $\begin{array}{l}\text { Body mass index } \\
\left(\mathrm{kg} / \mathrm{m}^{2}\right)\end{array}$ & $23.8 \pm 3.8$ & $23.0 \pm 2.8$ & 0.003 \\
\hline $\begin{array}{l}\text { Age at menopause } \\
\text { (years) }\end{array}$ & $48.7 \pm 4.4$ & - & - \\
\hline $\begin{array}{l}\text { Menopausal } \\
\text { duration (years) }\end{array}$ & $14.3 \pm 9.8$ & - & - \\
\hline TB BMD $\left(\mathrm{g} / \mathrm{cm}^{2}\right)$ & $1.031 \pm 0.106$ & $1.136 \pm 0.100$ & $<0.001$ \\
\hline LS BMD $\left(\mathrm{g} / \mathrm{cm}^{2}\right)$ & $0.812 \pm 0.146$ & $0.940 \pm 0.134$ & $<0.001$ \\
\hline TF BMD $\left(\mathrm{g} / \mathrm{cm}^{2}\right)$ & $0.727 \pm 0.130$ & $0.833 \pm 0.110$ & $<0.001$ \\
\hline FN BMD $\left(\mathrm{g} / \mathrm{cm}^{2}\right)$ & $0.612 \pm 0.117$ & $0.719 \pm 0.104$ & $<0.001$ \\
\hline $\mathrm{FM}(\mathrm{kg})$ & $20.4 \pm 5.6$ & $19.8 \pm 4.5$ & 0.130 \\
\hline LM (kg) & $34.2 \pm 4.6$ & $34.9 \pm 4.0$ & 0.072 \\
\hline PBF (\%) & $36.8 \pm 5.1$ & $35.8 \pm 3.8$ & 0.007 \\
\hline
\end{tabular}

Abbreviations: BMD, bone mineral density; TB, total body; LS, lumbar spine; TF, total femur; FN, femoral neck; FM, fat mass; LM, lean mass; PBF, percentage body fat.

the correlations between indices of body composition, subject characteristics, and BMD measurement. In postmenopausal women, both fat mass and lean mass were positively correlated with BMD. In addition, lean mass showed a stronger correlation than fat mass at all skeletal sites, with the highest and lowest value at the total femur and total body, respectively $(\mathrm{r}=0.548$ and $0.182, P<0.001)$. A significant positive correlation was also seen between fat mass and lean mass and BMD in perimenopausal women. Lean mass also showed a stronger correlation than fat mass in this group. However, no significant correlation was found for total body. In both groups of subjects, fat mass and lean mass were positively correlated with height, weight, body mass index, and BMD at all sites $(P<0.01)$. Fat mass and lean mass were also inversely correlated with age and duration since menopause $(P<0.001)$ in postmenopausal women. In univariate analysis, greater fat mass and lean mass were associated with higher BMD at the total body, lumbar spine, total femur, and femoral neck in both groups of women, except for fat mass and total body BMD in perimenopausal women (Table 3). Lean mass demonstrated a stronger association than fat mass at all sites. The results of multivariate linear regression analysis are shown in Table 4. In postmenopausal women, after adjusting for age, height, and duration since menopause, we observed that both fat mass and lean mass had a significantly positive association with BMD when analyzed separately from each other (model 1 and model 2). When both variables were included in the same equation (model 3), both
Table 2 Correlations between subject characteristics, body composition and BMD measurements

\begin{tabular}{|c|c|c|c|}
\hline Parameters & FM (kg) & LM (kg) & PBF (\%) \\
\hline \multirow[t]{4}{*}{ Age (years) } & $-0.12 *$ & $-0.28 *$ & -0.002 \\
\hline & $(<0.00 \mathrm{I})$ & $(<0.00 \mathrm{I})$ & $(0.952)$ \\
\hline & $0.234 *$ & 0.093 & $0.23 *$ \\
\hline & $(0.007)$ & $(0.289)$ & $(0.009)$ \\
\hline \multirow[t]{4}{*}{ Height (cm) } & $0.25 *$ & $0.54 *$ & 0.01 \\
\hline & $(0.001)$ & $(<0.00 \mathrm{I})$ & $(0.726)$ \\
\hline & $0.29 *$ & $0.89 *$ & 0.037 \\
\hline & $(<0.00 \mathrm{I})$ & $(<0.00 \mathrm{I})$ & $(0.677)$ \\
\hline \multirow[t]{4}{*}{ Weight (kg) } & $0.92 *$ & $0.89 *$ & $0.63^{*}$ \\
\hline & $(<0.00 \mathrm{I})$ & $(<0.00 \mathrm{I})$ & $(<0.00 \mathrm{I})$ \\
\hline & $0.92 *$ & $0.54 *$ & $0.57^{*}$ \\
\hline & $(<0.00 \mathrm{I})$ & $(<0.00 \mathrm{I})$ & $(<0.00 \mathrm{I})$ \\
\hline \multirow[t]{4}{*}{ BMI $\left(k g / m^{2}\right)$} & $0.88 *$ & $0.70 *$ & $0.70 *$ \\
\hline & $(<0.00 \mathrm{I})$ & $(<0.00 \mathrm{I})$ & $(<0.00 \mathrm{I})$ \\
\hline & $0.86 *$ & $0.7 I^{*}$ & $0.62 *$ \\
\hline & $(<0.00 \mathrm{I})$ & $(<0.00 \mathrm{I})$ & $(<0.00 \mathrm{I})$ \\
\hline Age at menopause & $0.07 *$ & 0.04 & $0.07^{*}$ \\
\hline \multirow[t]{2}{*}{ (years) } & $(0.007)$ & (0.099) & $(0.009)$ \\
\hline & - & - & - \\
\hline Menopause duration & $-0.14^{*}$ & $-0.29 *$ & -0.03 \\
\hline \multirow[t]{2}{*}{ (years) } & $(<0.00 \mathrm{I})$ & $(<0.00 \mathrm{I})$ & $(0.216)$ \\
\hline & - & - & - \\
\hline \multirow[t]{4}{*}{ TB BMD $\left(\mathrm{g} / \mathrm{cm}^{2}\right)$} & $0.18 *$ & $0.40^{*}$ & 0.10 \\
\hline & $(<0.00 \mathrm{I})$ & $(<0.00 \mathrm{I})$ & $(0.705)$ \\
\hline & 0.17 & $0.34 *$ & 0.02 \\
\hline & (0.059) & $(<0.00 \mathrm{I})$ & $(0.86 \mathrm{I})$ \\
\hline \multirow[t]{4}{*}{ LS BMD $\left(\mathrm{g} / \mathrm{cm}^{2}\right)$} & $0.38 *$ & $0.47^{*}$ & $0.215^{*}$ \\
\hline & $(<0.00 \mathrm{I})$ & $(<0.00 \mathrm{I})$ & $(<0.00 \mathrm{I})$ \\
\hline & $0.205^{*}$ & $0.348^{*}$ & 0.07 \\
\hline & $(0.019)$ & $(<0.00 \mathrm{I})$ & $(0.435)$ \\
\hline \multirow[t]{4}{*}{ TF BMD $\left(\mathrm{g} / \mathrm{cm}^{2}\right)$} & $0.42 *$ & $0.55^{*}$ & $0.22 *$ \\
\hline & $(<0.00 \mathrm{I})$ & $(<0.00 \mathrm{I})$ & $(<0.001)$ \\
\hline & $0.27^{*}$ & $0.51 *$ & 0.03 \\
\hline & $(0.002)$ & $(<0.00 \mathrm{I})$ & $(0.754)$ \\
\hline \multirow[t]{4}{*}{ FN BMD $\left(\mathrm{g} / \mathrm{cm}^{2}\right)$} & $0.40 *$ & $0.53 *$ & $0.21 *$ \\
\hline & $(<0.00 \mathrm{I})$ & $(0.001)$ & $(<0.00 \mathrm{I})$ \\
\hline & $0.26^{*}$ & $0.47^{*}$ & 0.04 \\
\hline & $(0.003)$ & $(<0.00 \mathrm{I})$ & $(0.674)$ \\
\hline
\end{tabular}

Notes: Numbers represent Pearson's correlation coefficients ( $P$-value). The values of the Ist and the 3rd row represent coefficients of postmenopausal and perimenopusal groups respectively. $* P$-value $<0.05$ (two-tailed).

Abbreviations: $\mathrm{BMD}$, bone mineral density; TB, total body; LS, lumbar spine; TF, total femur; FN, femoral neck; FM, fat mass; LM, lean mass; PBF, percentage body fat.

fat mass and lean mass continued to show significant positive regression coefficients, but lean mass had a significantly greater effect than fat mass on BMD at all sites except for total body (where fat mass had a negative effect on BMD). In perimenopausal women, after adjusting for age and height, we only found a significantly positive regression coefficient for fat mass and total femur BMD $(\beta=0.00478, P=0.014)$, while a significant positive correlation with lean mass was found at all sites where BMD was measured. In model 3, 
Table 3 The independent contribution of each individual variable to BMD at different skeletal sites by univariable linear regression analyses

\begin{tabular}{|c|c|c|c|c|c|c|c|c|}
\hline \multirow[t]{2}{*}{ Skeletal sites } & \multicolumn{2}{|l|}{ TB BMD } & \multicolumn{2}{|l|}{ LS BMD } & \multicolumn{2}{|l|}{ TF BMD } & \multicolumn{2}{|l|}{ FN BMD } \\
\hline & $\beta$ & $P$-value & $\beta$ & $P$-value & $\beta$ & $P$-value & $\beta$ & $P$-value \\
\hline \multicolumn{9}{|l|}{ Postmenopausal women } \\
\hline Age & $-0.00510 *$ & $<0.001$ & $-0.00473 *$ & $<0.001$ & $-0.00702^{*}$ & $<0.001$ & $-0.00628 *$ & $<0.001$ \\
\hline Height & $0.00672 *$ & $<0.001$ & $0.00756^{*}$ & $<0.001$ & $0.00878^{*}$ & $<0.001$ & $0.00822 *$ & $<0.001$ \\
\hline Menopause duration & $-0.00479 *$ & $<0.001$ & $-0.00463^{*}$ & $<0.001$ & $-0.00647^{*}$ & $<0.001$ & $-0.00586 *$ & $<0.001$ \\
\hline $\mathrm{FM}$ & $0.00345 *$ & $<0.001$ & $0.00982 *$ & $<0.001$ & $0.00965^{*}$ & $<0.001$ & $0.00846 *$ & $<0.001$ \\
\hline LM & $0.00912 *$ & $<0.001$ & $0.01486 *$ & $<0.001$ & $0.01542^{*}$ & $<0.001$ & $0.01359 *$ & $<0.001$ \\
\hline \multicolumn{9}{|l|}{ Perimenopausal women } \\
\hline Age & -0.00142 & 0.472 & -0.00130 & 0.626 & 0.00958 & 0.661 & -0.00045 & 0.826 \\
\hline Height & $0.00550 *$ & 0.001 & $0.00924^{*}$ & $<0.001$ & $0.00713^{*}$ & $<0.001$ & $0.00866 *$ & $<0.001$ \\
\hline $\mathrm{FM}$ & 0.00369 & 0.059 & $0.006 \mid 4^{*}$ & 0.019 & $0.00668^{*}$ & 0.002 & $0.00595^{*}$ & 0.003 \\
\hline LM & $0.00849 *$ & $<0.001$ & $0.01171 *$ & $<0.001$ & $0.01400 *$ & $<0.001$ & $0.01233 *$ & $<0.001$ \\
\hline
\end{tabular}

Note: $* P$-value $<0.05$

Abbreviations: BMD, bone mineral density; TB, total body; LS, lumbar spine; TF, total femur; FN, femoral neck; FM, fat mass; LM, lean mass.

lean mass remained the stronger positive variable for BMD at all sites except the lumbar spine. Fat mass seemed to have a negative association with BMD at all sites; however, these associations were not statistically significant. Neither fat mass nor lean mass was significantly associated with BMD at the lumbar spine. In summary, our findings show that, in general, both fat mass and lean mass were positively associated with BMD in postmenopausal women, but the effect of lean mass on BMD was greater than that of fat mass. Only lean mass showed a positive effect on BMD in perimenopausal women.

\section{Discussion}

The respective contribution of the components of body composition to BMD remains controversial. Some studies have shown a positive association between lean mass and $\mathrm{BMD}^{7,9,11,13,15,20-22}$ and others have reported that only fat mass is associated with BMD. ${ }^{2,3,15-17}$ The results of some studies showed that fat mass and lean mass were both associated with BMD. ${ }^{13,19,23-26}$ Further, an adverse effect of fat mass on BMD has been reported in some studies. ${ }^{12,27}$ These inconsistent findings may be attributable to many factors, including study design, statistical analysis, menopausal status, and the skeletal sites measured.

In this study, we evaluated the relative importance of body composition (fat mass and lean mass) to BMD at different skeletal sites. This cross-sectional study was based on a large population representative of healthy postmenopausal and perimenopausal women, and is the first paper, as far

Table 4 Multivariable linear regression analyses of BMD at different skeletal sites against the body composition variables

\begin{tabular}{|c|c|c|c|c|c|c|c|c|}
\hline \multirow[t]{2}{*}{ Skeletal sites } & \multicolumn{2}{|l|}{ TB BMD } & \multicolumn{2}{|l|}{ LS BMD } & \multicolumn{2}{|l|}{ TF BMD } & \multicolumn{2}{|l|}{ FN BMD } \\
\hline & $\beta$ & $P$-value & $\beta$ & $P$-value & $\beta$ & $P$-value & $\beta$ & $P$-value \\
\hline \multicolumn{9}{|c|}{ Postmenopausal women* } \\
\hline \multicolumn{9}{|c|}{ Model I: BMD = f (FM) } \\
\hline FM & 0.00153 & 0.001 & 0.00813 & $<0.001$ & 0.00747 & $<0.00$ I & 0.00640 & $<0.001$ \\
\hline \multicolumn{9}{|c|}{ Model 2: $B M D=f(L M)$} \\
\hline LM & 0.00565 & $<0.001$ & 0.01299 & $<0.001$ & 0.01228 & $<0.00$ I & 0.01034 & $<0.001$ \\
\hline \multicolumn{9}{|c|}{ Model 3: BMD = $f(F M, L M)$} \\
\hline FM & -0.00219 & 0.002 & 0.00343 & $<0.001$ & 0.00285 & $<0.001$ & 0.00261 & $<0.001$ \\
\hline LM & 0.00772 & $<0.001$ & 0.00974 & $<0.001$ & 0.00956 & $<0.001$ & 0.00787 & $<0.001$ \\
\hline \multicolumn{9}{|c|}{ Perimenopausal women** } \\
\hline \multicolumn{9}{|c|}{ Model I: BMD = f (FM) } \\
\hline FM & 0.00209 & 0.249 & 0.00345 & 0.266 & 0.00478 & 0.014 & 0.00345 & 0.062 \\
\hline \multicolumn{9}{|c|}{ Model 2: $B M D=f(L M)$} \\
\hline LM & 0.00671 & 0.003 & 0.00772 & 0.076 & 0.01290 & $<0.001$ & 0.00913 & $<0.001$ \\
\hline \multicolumn{9}{|c|}{ Model 3: $B M D=f(F M, L M)$} \\
\hline FM & -0.00197 & 0.566 & -0.00053 & 0.915 & -0.00250 & 0.317 & -0.00166 & 0.512 \\
\hline LM & 0.00828 & 0.047 & $0.008 \mid 4$ & 0.216 & 0.01489 & $<0.001$ & 0.01045 & 0.002 \\
\hline
\end{tabular}

Notes: *Models were adjusted for age, height, and menopause duration in postmenopausal women; **models were adjusted for age, height in perimenopausal women. Abbreviations: BMD, bone mineral density; TB, total body; LS, lumbar spine; TF, total femur; FN, femoral neck; FM, fat mass; LM, lean mass. 
as we know, on body composition measured by dual x-ray absorptiometry in Thai women. Our results show evidence of a positive relationship between body composition and BMD. However, this relationship differed according to menopausal status. In postmenopausal women, we found a correlation between lean mass and BMD throughout the skeleton $(0.40<r<0.55)$, which was somewhat greater than that seen for fat mass $(0.18<r<0.42)$. Both fat mass and lean mass were associated significantly with BMD, and lean mass had a greater impact than fat mass at all three principal skeletal sites for a diagnosis of osteoporosis (lumbar spine, total femur, and femoral neck). This further supports the hypothesis of muscle-mediated mechanical loads (lean mass) on $\mathrm{BMD}^{8}$ and a lesser complementary effect of fat mass on bone in postmenopausal women. The greatest effect for both lean mass and fat mass was found in the trabecular bone at the lumbar spine, followed by the total femur and femoral neck, which are a mixture of trabecular and cortical bone. For the total body (cortical bone) region, lean mass still had a positive effect on BMD, but fat mass showed a significantly negative association. The data presented here indicate that lean mass and fat mass have different effects on cortical and trabecular BMD. In perimenopausal women, lean mass was the main determinant of BMD and fat mass had neither a positive nor a negative impact on BMD, which is consistent with previous studies. ${ }^{15,28}$ However, a positive effect was only demonstrated at the total femur, femoral neck, and total body, and not at the lumbar spine. Based on these results, we assume that the effect of lean mass was predominantly on cortical bone and had little effect on trabecular bone in perimenopausal women.

In this study, the association between body composition and BMD was inconsistent. A positive effect of lean mass on BMD was demonstrated in both postmenopausal and perimenopausal women. The results related to fat mass observed in postmenopausal women were not observed in perimenopausal women. The inverse relationship between fat mass in perimenopausal women and bone mass was not statistically significant in this study. Our observation is not consistent with previous studies showing that fat mass and percentage body fat have an adverse effect on bone mass, mostly in children and young adult females. ${ }^{29-31}$ Zhao et al found a positive correlation between fat mass and bone mass in Chinese and white subjects. However, after adjusting for the mechanical effect caused by lean mass, fat mass is negatively correlated with bone mass, suggesting that fat mass actually has a detrimental effect on bone. ${ }^{32}$ In summary, our study suggests that the effect of fat mass was related to menopausal status (ie, the estrogen source). In perimenopausal women, ovarian estrogen plays a greater role than aromatized estrogen. ${ }^{33,34}$ In contrast, after menopause, fat tissue can produce aromatized estrogen, which is the major source of estrogen. ${ }^{35,36}$ Therefore, the beneficial effect of fat mass on BMD is primarily related to aromatized estrogen.

The strengths of this study are its large size, inclusion of both postmenopausal and perimenopausal women, and measurement of BMD at several skeletal sites. Because the proportions of trabecular and cortical components differ according to skeletal site, we were able to estimate the effect of body composition on each type of bone measured. However, our study also has several limitations. First, we could not control for relevant lifestyle and dietary factors, such as eating habits, calcium intake, smoking history, and physical activity, because these data were not available. Second, the cross-sectional design of this study precludes any inferences about causality, and our findings cannot be generalized to other ethnic groups. Third, our study yielded inconsistent results between perimenopausal and postmenopausal groups, which may have resulted from the small sample size of the perimenopausal group.

In conclusion, our data show that, in Thai women, the effect of fat mass and lean mass varied according to the skeletal site measured and menopausal status. Lean mass had a significant positive effect on BMD in both postmenopausal and perimenopausal women, and can be considered as one of the determinants of bone mass. The effect of fat mass was related to menopausal status and only demonstrated a beneficial impact in perimenopausal women.

\section{Acknowledgment}

This work was funded by the Faculty of Medicine Research Fund, Chiang Mai University, Chiang Mai, Thailand.

\section{Disclosure}

The authors report no conflicts of interest in this work.

\section{References}

1. Rosen CJ, Bouxsein ML. Mechanisms of disease: is osteoporosis the obesity of bone? Nat Clin Pract Rheumatol. 2006;2(1):35-43.

2. Reid IR, Ames R, Evans MC, et al. Determinants of total body and regional bone mineral density in normal postmenopausal women a key role for fat mass. J Clin Endocrinol Metab. 1992;75(1):45-51.

3. Reid IR, Plank LD, Evans MC. Fat mass is an important determinant of whole body bone density in premenopausal women but not in men. J Clin Endocrinol Metab. 1992;75(3):779-782.

4. Felson DT, Zhang Y, Hannan MT, Anderson JJ. Effects of weight and body mass index on bone mineral density in men and women: the Framingham study. J Bone Miner Res. 1993;8(5):567-573.

5. Marcus R, Greendale G, Blunt BA, et al. Correlates of bone mineral density in the postmenopausal estrogen/progestin interventions trial. J Bone Miner Res. 1994;9(9):1467-1476. 
6. Ravn P, Cizza G, Bjarnason NH, et al. Low body mass index is an important risk factor for low bone mass and increased bone loss in early postmenopausal women. Early Postmenopausal Intervention Cohort (EPIC) study group. J Bone Miner Res. 1999;14(9):1622-1627.

7. Chen Z, Lohman TG, Stini WA, Ritenbaugh C, Aickin M. Fat or lean tissue mass: which one is the major determinant of bone mineral mass in healthy postmenopausal women? J Bone Miner Res. 1997;12(1): $144-151$.

8. Blum M, Harris SS, Must A, et al. Leptin, body composition and bone mineral density in premenopausal women. Calcif Tissue Int. 2003; 73(1):27-32.

9. Douchi T, Kuwahata R, Matsuo T, Uto H, Oki T, Nagata Y. Relative contribution of lean and fat mass component to bone mineral density in males. J Bone Miner Metab. 2003;21(1):17-21.

10. Liu JM, Zhao HY, Ning G, et al. Relationship between body composition and bone mineral density in healthy young and premenopausal Chinese women. Osteoporos Int. 2004;15(3):238-242.

11. Wang MC, Bachrach LK, Van Loan M, Hudes M, Flegal KM, Crawford PB. The relative contributions of lean tissue mass and fat mass to bone density in young women. Bone. 2005;37(4):474-481.

12. Hsu YH, Venners SA, Terwedow HA, et al. Relation of body composition, fat mass, and serum lipids to osteoporotic fractures and bone mineral density in Chinese men and women. Am J Clin Nutr. 2006;83(1):146-154.

13. Cheng Q, Zhu YX, Zhang MX, Li LH, Du PY, Zhu MH. Age and sex effects on the association between body composition and bone mineral density in healthy Chinese men and women. Menopause. 2012;19(4):448-455.

14. Andreoli A, Bazzocchi A, Celi M, et al. Relationship between body composition, body mass index and bone mineral density in a large population of normal, osteopenic and osteoporotic women. Radiol Med. 2011;116(7):1115-1123.

15. Li S, Wagner R, Holm K, Lehotsky J, Zinaman MJ. Relationship between soft tissue body composition and bone mass in perimenopausal women. Maturitas. 2004;47(2):99-105.

16. Khosla S, Atkinson EJ, Riggs BL, Melton LJ 3rd. Relationship between body composition and bone mass in women. J Bone Miner Res. 1996;11(6):857-863.

17. Cui LH, Shin MH, Kweon SS, et al. Relative contribution of body composition to bone mineral density at different sites in men and women of South Korea. J Bone Miner Metab. 2007;25(3):165-171.

18. El Hage R, Jacob C, Moussa E, Baddoura R. Relative importance of lean mass and fat mass on bone mineral density in a group of Lebanese postmenopausal women. J Clin Densitom. 2011;14(3):326-331.

19. Sheng Z, Xu K, Ou Y, et al. Relationship of body composition with prevalence of osteoporosis in central south Chinese postmenopausal women. Clin Endocrinol (Oxf). 2011;74(3):319-324.

20. Gnudi S, Sitta E, Fiumi N. Relationship between body composition and bone mineral density in women with and without osteoporosis: relative contribution of lean and fat mass. J Bone Miner Metab. 2007;25(5): $326-332$.
21. Gomez-Cabello A, Ara I, Gonzalez-Aguero A, Casajus JA, Vicente-Rodriguez G. Fat mass influence on bone mass is mediated by the independent association between lean mass and bone mass among elderly women: a cross-sectional study. Maturitas. 2013;74(1):44-53.

22. Park JH, Song YM, Sung J, et al. The association between fat and lean mass and bone mineral density: the Healthy Twin Study. Bone. 2012;50(4):1006-1011.

23. Khosla S, Atkinson EJ, Riggs BL, Melton LJ 3rd. Relationship between body composition and bone mass in women. J Bone Miner Res. 1996;11(6):857-863.

24. Lim S, Joung H, Shin CS, et al. Body composition changes with age have gender-specific impacts on bone mineral density. Bone. 2004;35(3): 792-798.

25. Gillette-Guyonnet S, Nourhashemi F, Lauque S, Grandjean H, Vellas B. Body composition and osteoporosis in elderly women. Gerontology. 2000;46(4):189-193.

26. Pluijm SM, Visser M, Smit JH, Popp-Snijders C, Roos JC, Lips P. Determinants of bone mineral density in older men and women: body composition as mediator. J Bone Miner Res. 2001;16(11): 2142-2151.

27. Yu Z, Zhu Z, Tang T, Dai K, Qiu S. Effect of body fat stores on total and regional bone mineral density in perimenopausal Chinese women. J Bone Miner Metab. 2009;27(3):341-346.

28. Salamone LM, Glynn N, Black D, et al. Body composition and bone mineral density in premenopausal and early perimenopausal women. J Bone Miner Res. 1995;10(11):1762-1768.

29. Arimatsu M, Kitano T, Kitano N, Inomoto T, Shono M, Futatsuka M. Correlation between forearm bone mineral density and body composition in Japanese females aged 18-40 years. Environ Health Prev Med. 2005;10(3):144-149.

30. Arimatsu M, Kitano T, Kitano N, Futatsuka M. Correlation between bone mineral density and body composition in Japanese females aged 18-40 years with low forearm bone mineral density. Environ Health Prev Med. 2009;14(1):46-51.

31. Weiler HA, Janzen L, Green K, Grabowski J, Seshia MM, Yuen KC. Percent body fat and bone mass in healthy Canadian females 10 to 19 years of age. Bone. 2000;27(2):203-207.

32. Zhao LJ, Liu YJ, Liu PY, Hamilton J, Recker RR, Deng HW. Relationship of obesity with osteoporosis. J Clin Endocrinol Metab. 2007;92(5):1640-1646.

33. Prior JC. Perimenopause: the complex endocrinology of the menopausal transition. Endocr Rev. 1998;19(4):397-428.

34. Burger HG, Dudley EC, Robertson DM, Dennerstein L. Hormonal changes in the menopause transition. Recent Prog Horm Res. 2002;57: 257-275.

35. Reid IR. Relationships among body mass, its components, and bone. Bone. 2002;31(5):547-555.

36. Simpson ER. Sources of estrogen and their importance. J Steroid Biochem Mol Biol. 2003;86(3-5):225-230.
International Journal of Women's Health

\section{Publish your work in this journal}

The International Journal of Women's Health is an international, peerreviewed open-access journal publishing original research, reports, editorials, reviews and commentaries on all aspects of women's healthcare including gynecology, obstetrics, and breast cancer. The manuscript management system is completely online and includes

\section{Dovepress}

a very quick and fair peer-review system, which is all easy to use. Visit http://www.dovepress.com/testimonials.php to read real quotes from published authors. 